UCRL-ID-120385

\title{
Development of Non-Hazardous Explosives for Security Training and Testing (NESTT)
}

\author{
J.W. Kury \\ R.L. Simpson
}

June 21, 1995

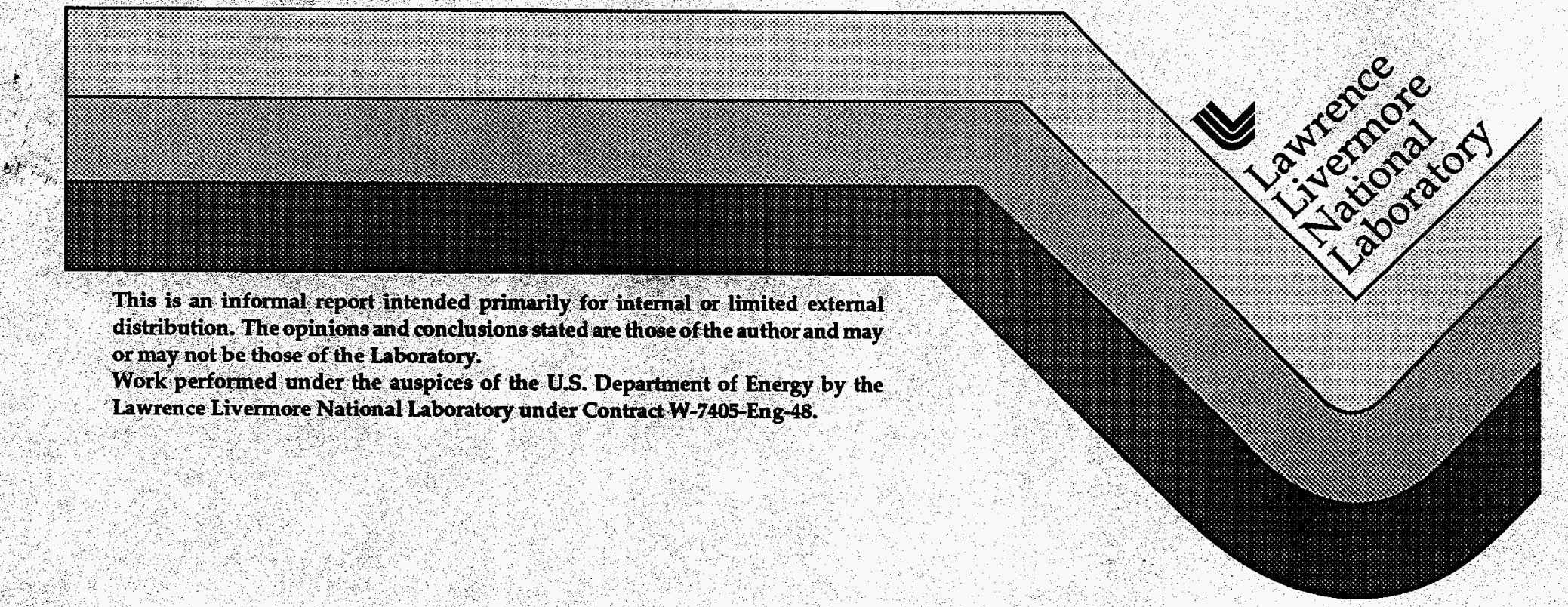




\section{DISCLAIMER}

This report was prepared as an account of work sponsored by an agency of the United States Government. Neither the United States Government nor any agency thereof, nor any of their employees, make any warranty, express or implied, or assumes any legal liability or responsibility for the accuracy, completeness, or usefulness of any information, apparatus, product, or process disclosed, or represents that its use would not infringe privately owned rights. Reference herein to any specific commercial product, process, or service by trade name, trademark, manufacturer, or otherwise does not necessarily constitute or imply its endorsement, recommendation, or favoring by the United States Government or any agency thereof. The views and opinions of authors expressed herein do not necessarily state or reflect those of the United States Government or any agency thereof. 


\section{DISCLAIMER}

Portions of this document may be illegible in electronic image products. Images are produced from the best available original document. 


\title{
Development of Non-Hazardous Explosives for $\underline{\text { Security }}$ Training and Testing (NESTT)
}

\author{
J.W. Kury and R.L. Simpson \\ Energetic Materials Center \\ Chemistry \& Materials Science Directorate
}

\begin{abstract}
A series of materials has been prepared that have authentic properties of explosives but are non-hazardous. These NESTT materials are prepared by coating a few micron thick layer of an explosive on a non-reactive substrate. This produces a formulation with an authentic vapor and molecular signature. Authentic $x$-ray and oxygen/nitrogen density signatures are obtained through the appropriate choice of a substrate. The signatures of NESTT TNT and NESTT Comp. C-4 have been verified by instrument and K-9 detection in a Beta Test Program.
\end{abstract}

\section{Introduction}

The security force at the Lawrence Livermore National Laboratory (LLNL) routinely used canines to search for explosives and other contraband substances. The use of threat quantities of explosive for realistic training in populated or sensitive Laboratory areas has not been permitted because of the hazard. To overcome this limitation a series of non-hazardous materials with authentic signatures have been prepared and evaluated.

Two classes of materials were made; one for K-9 detection studies and another for instrument detection studies. Authentic signatures were obtained by coating a small quantity of the parent explosive onto especially selected organic/inorganic substrates. The materials were non hazardous if the concentration of the parent explosive remained under approximately $15 \%$.

Preliminary results were so successful that NESTT versions of two commonly used explosives were prepared in larger quantities for a Beta Test Program. The testing program involved both United States and foreign instrument companies and K-9 explosive detection units. This report describes the preparation, properties and preliminary test results obtained for NESTT versions of TNT and Comp. C-4.

\section{Material Preparation}

NESTT materials for use in the training and reinforcement of explosive detecting canines must have no additional odors present than those found in the parent explosive. To insure this, high purity fused silica was used as the substrate. NESTT materials for use in instrument detection studies used appropriate organic and inorganic substrates 
to match the parent explosive's $x$-ray signature and nitrogen/oxygen densities characteristic of explosives. The compositions of the three NESTT materials used in the Beta Test Program are listed in Table 1. They are preliminary versions of an "instrument" NESTT for Comp. C-4 and "K-9" NESTTs for TNT and Comp. C-4.

Table 1. NESTT Compositions Use in the Beta Test Program

\begin{tabular}{|c|c|c|c|}
\hline Name & $\begin{array}{l}\text { Composition }{ }^{a} \\
(w t \%)\end{array}$ & $\begin{array}{l}\text { Density } \\
(\mathrm{g} / \mathrm{cc})\end{array}$ & Remarks \\
\hline KTN-01-AA & $\begin{array}{c}8 \% \text { TNT } \\
92 \% \text { silica }\end{array}$ & 0.97 & $\begin{array}{l}\text { This material has the K-9 odor } \\
\text { "signature" of TNT }\end{array}$ \\
\hline KTN-04-AA & $\begin{array}{c}8.0 \% \text { RDX } \\
9.2 \% \text { DOA } \\
2.7 \% \text { PIB } \\
3.6 \% \text { oil } \\
76.5 \% \text { silica }\end{array}$ & 1.54 & $\begin{array}{l}\text { This material has the K-9 odor } \\
\text { "signature" of Comp. C- } 4 \text {. }\end{array}$ \\
\hline IN-04-AA & \begin{tabular}{|l|}
$7.4 \%$ RDX \\
$78.5 \%$ cyanuric acid \\
$8.3 \%$ DOA \\
$3.3 \%$ PIB \\
$2.5 \%$ oil
\end{tabular} & 1.42 & $\begin{array}{l}\text { This material has the same effective } \\
\text { atomic number as Comp. C-4; the } \\
\text { oxygen/nitrogen density } \\
\text { characteristic of explosives; and } \\
\text { contains RDX. Its density is about } \\
10 \% \text { lower than that of Comp. C-4 }\end{array}$ \\
\hline
\end{tabular}

a TNT $=$ 2-methyl-1,3,5-trinitrobenzene

$\mathrm{RDX}=$ hexahydro-1,3,5-trinitro-1,3,5-triazine

$\mathrm{PIB}=$ polyisobutylene

$\mathrm{DOA}=$ dioctal adipate

Estane $=$ polyurethane binder, $\left(\mathrm{C}_{5.14} \mathrm{H}_{7.50} \mathrm{~N}_{0.19} 0_{1.76}\right)_{\mathrm{n}}$

KTN-01-AA was prepared by dissolving TNT in acetone and then adding silica to this solution in a high sheer mixer. The acetone was stripped off while mixing and then dried in an oven. This resulted in a granular material with a bulk density of about $1 \mathrm{~g} / \mathrm{cc}$. Microscopic examination showed that some areas of the silica were coated and some had small crystals of TNT adhering to the surface. Samples for testing were packaged in containers similar to those used for military demolition charges and also in plastic bags.

KTN-04-AA was prepared by first dissolving RDX in acetone and then adding silica to this solution. The acetone was removed using a rotary evaporator and the granular product was then dried in an oven. Next, PIB, DOA, and oil were dissolved in pentane and combined with the granular RDX/silica material in a high sheer mixer. The pentane was stripped while mixing and the resultant putty like material was then oven dried. Bars measuring $2.5 \times 5.0 \times 30.5 \mathrm{~cm}$ were molded and encased in plastic. (Packaging was identical to the M 112 Comp. C-4 demolition bars produced by the Army.) Both bars and putty material supplied in plastic bags were used in the Beta Test Program. 
IN-04-AA was prepared by dissolving PIB, DOA and oil in pentane. This solution, RDX and cyanuric acid were added to a high sheer mixer. The pentane was removed while mixing. The resultant putty material was dried in an oven and then was packaged like KTN-04-AA for use in the instrument portion of the Beta Test Program.

As part of the EMC partnering-with-industry program GenCorp Aerojet ${ }^{1}$ has been licensed to produce and market NESTT materials for use in both K-9 and instrument explosive detection efforts. Commercial samples are expected to become available by Fall 1995.

\section{Hazards Testing of NESTT Materials}

NESTT materials have been tested both in small scale laboratory safety tests and the larger scale United Nations (UN) approved hazards classification tests. In addition a large number of tests have been carried out by the Department of Defense (DoD) on both TNT and RDX mixtures with sand and other inert materials. As a result, Department of Transportation (DOT) has concurred that all mixtures of $8 \%$ or less of TNT or RDX with an inert are not classified as explosives (not Class 1 materials).

The small scale impact and thermal tests are summarized in Table 2. No positive reactions were observe on the drop hammer or spark sensitivity tests. The thermal stability results were similar to those of the parent explosive (TNT or RDX).

Table 2. Small-scale safety test results.

\begin{tabular}{|c|c|c|c|c|}
\hline & $\begin{array}{c}\text { Impacta }^{\mathrm{a}} \\
\text { Sensitivity } \\
(\mathrm{cm})\end{array}$ & $\begin{array}{c}\text { Sparkb } \\
\text { Sensitivity }\end{array}$ & $\begin{array}{l}\text { CRT Gas } \\
\text { Evolution } \\
\left(\mathrm{cm}^{3} / \mathrm{kg}\right)\end{array}$ & $\begin{array}{c}\mathrm{DSC}^{\mathrm{d}} \\
\text { Exotherm } \\
\left({ }^{\circ} \mathrm{C}\right)\end{array}$ \\
\hline KTN-01-AA & $>177$ & no reaction & 32 & $>200$ \\
\hline KTN-04-AA & $>177$ & no reaction & 100 & $>200$ \\
\hline IN-04-AA & $>177$ & no reaction & 50 & $>200$ \\
\hline $\begin{array}{ll}\text { a } & 2.5 \mathrm{~kg} \text { Type } \\
\text { b } & 1 \mathrm{~J} \text { with } 510 \mathrm{~s} \\
\mathrm{c} & \text { Chemical re }\end{array}$ & $\begin{array}{l}\text { line resistan } \\
\text { vity test. Ga }\end{array}$ & & & \\
\hline
\end{tabular}

The NESTT materials containing TNT or RDX were submitted to UN large scale sensitivity tests. The materials did not react in the shock sensitivity tests or the fire tests. Similar results were obtained by the DoD when testing mixtures of $15 \%$ or less of TNT or RDX mixed with sand in the UN zero-gap shock test or the DDT test. 


\section{NESTT Instrument Test Results}

The Naval Research Laboratory (NRL) is developing methods to detect explosives using nuclear quadrupole resonance (NQR). They were provided samples of both the RDX-containing NESTT materials. They found a ${ }^{14} \mathrm{~N} N Q R$ resonance at 3.41 MHz for RDX in NESTT identical to that determined for RDX in Comp. C-4. The line width of this resonance is in the range of those seen for RDX in actual explosive compositions (See Figure 1). These results for NESTT Comp. C-4 and real Comp. C-4 were obtained by Quantum Magnetics ${ }^{2}$ using a prototype detector made under NRL license.

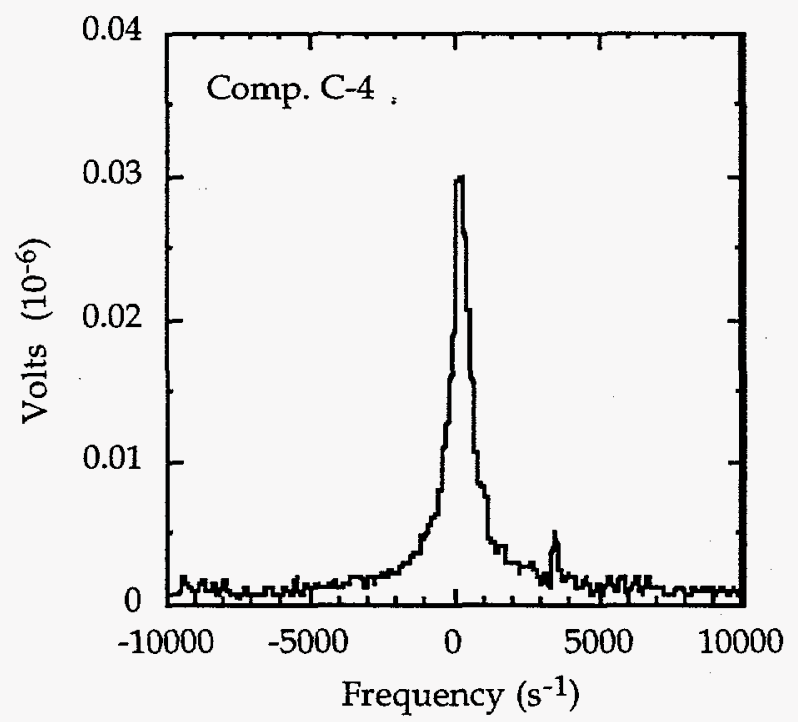

(a)

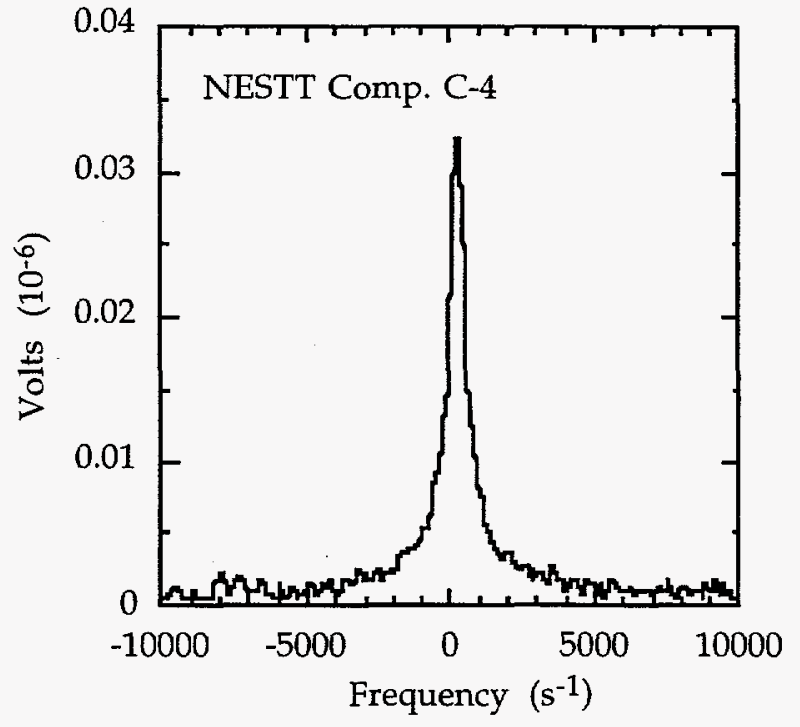

(b)

Figure 1. Nuclear quadrupole resonance spectra for: (a) explosive Comp. C-4 and (b) NESTT Comp. C-4.

NRL has also made preliminary measurements with NESTT TNT. Eleven ${ }^{14} \mathrm{~N}$ NQR lines were observed. The frequency of the lines agree with the literature values for the monoclinic phase of TNT. Their report indicates that the non-hazardous NESTT materials are "extremely useful in the laboratory and in conducting off site demonstrations".

Both TNT- and RDX-containing NESTT materials were tested by Thermedics Inc. ${ }^{3}$ using their EGIS detection system. Vapor and particulate samples are collected and explosives are identified by analysis of selected decomposition products. The NESTT materials were carried to Thermedics' laboratory in a brief case. The results, shown in Figure 2, indicate the presence of explosive not only in the NESTT sample itself, but also on the box and briefcase containing the materials. (The following day an explosive detecting K-9 also reacted positively to the then empty but still contaminated briefcase.) 


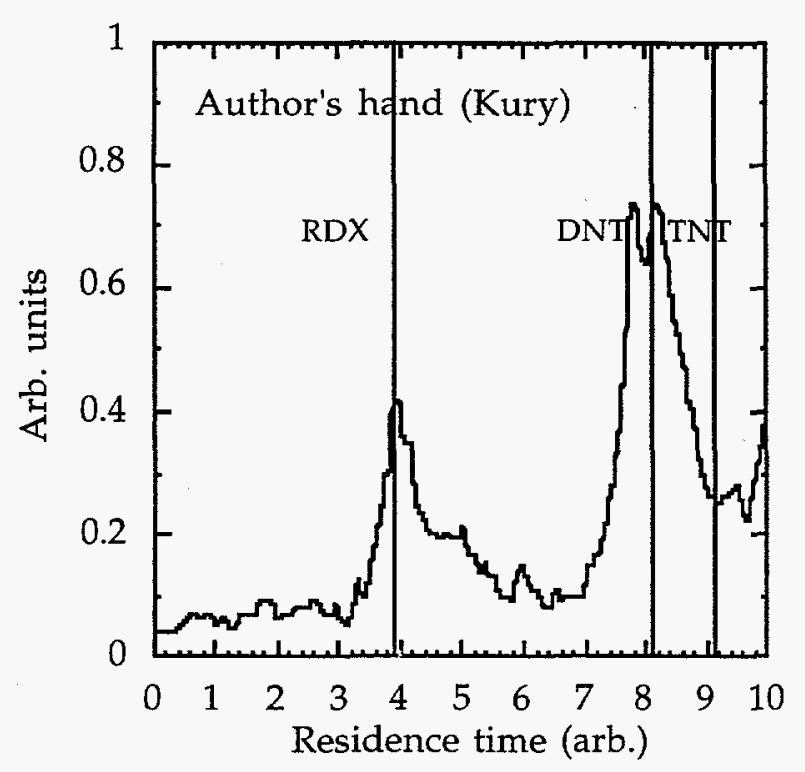

(a)

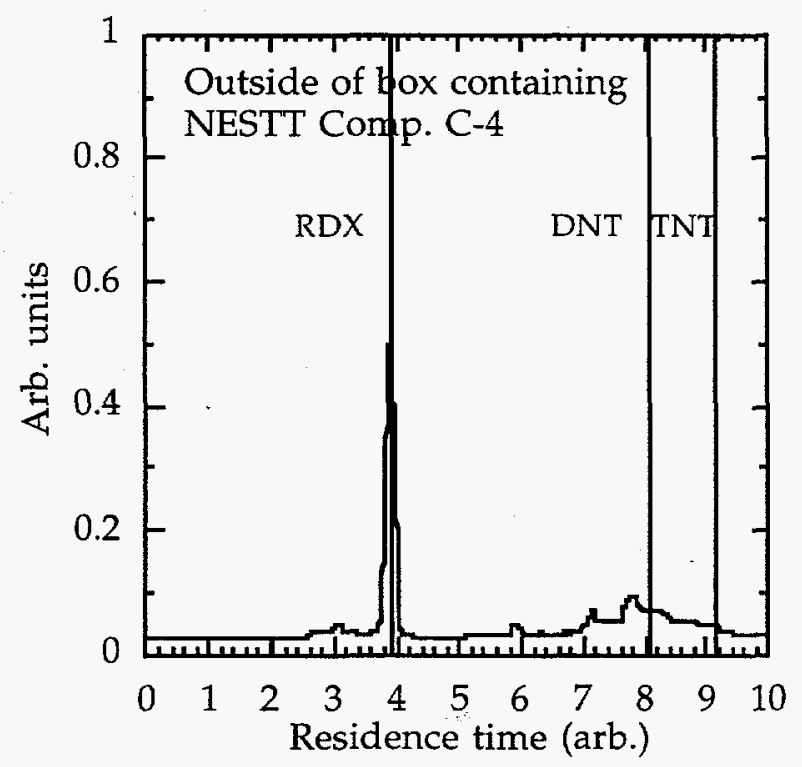

(c)

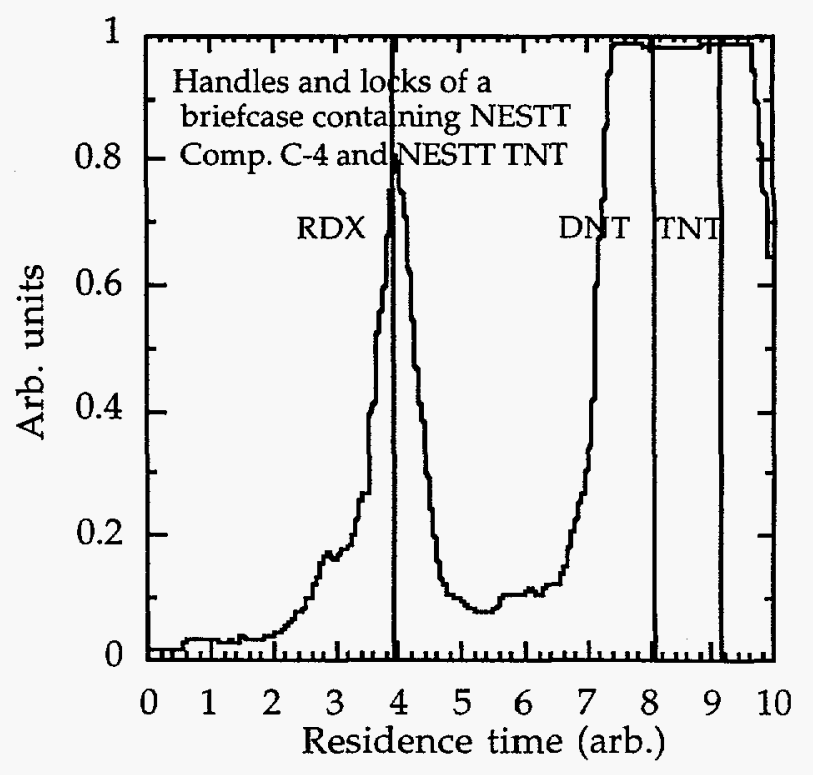

(b)

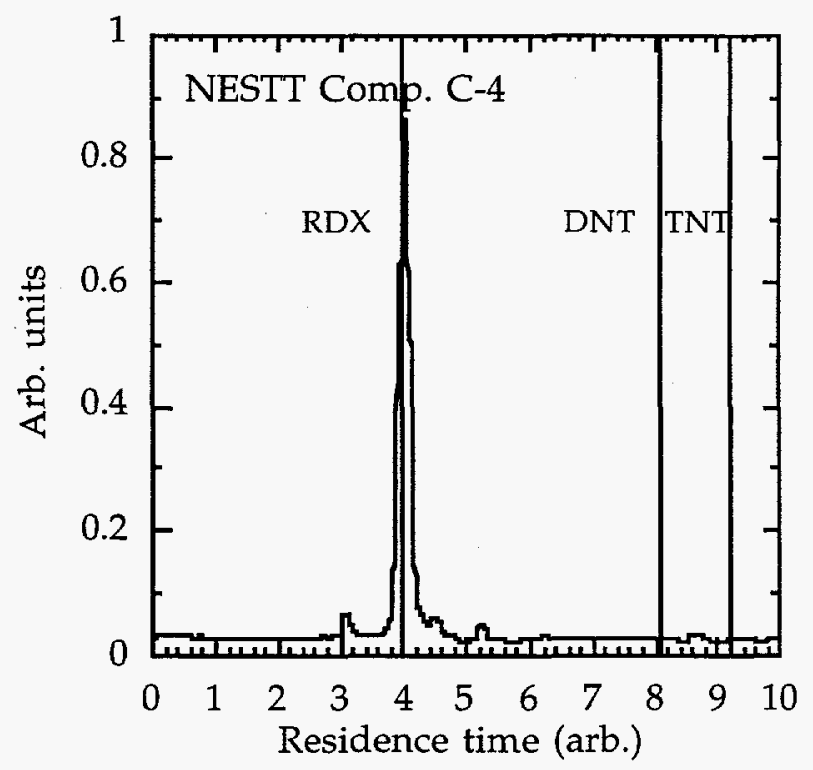

(d)

Figure 2. Thermedics' chromatographic analysis of thermal decomposition products of samples obtained from: (a) Author's hands prior to opening briefcase. DNT is present in TNT as a normal contaminant (b) Briefcase containing "sealed" NESTT samples (c) Outside of box containing NESTT Comp. C-4 (RDX) (d) Mylar sealed sample of NESTT Comp. C-4. Note: DNT = dinitrobenzene.

The instrument NESTT Comp. C- 4 was tested on both Invision's ${ }^{4}$ and VIVID's ${ }^{5}$ $x$-ray explosive detection equipment. Both gave positive results indicating that NESTT had the same effective atomic number and density as a real explosive sample. Figure 3 
shows the VIVID instrument's screen display for the NESTT samples to be the same as for their calibration samples. ${ }^{3}$

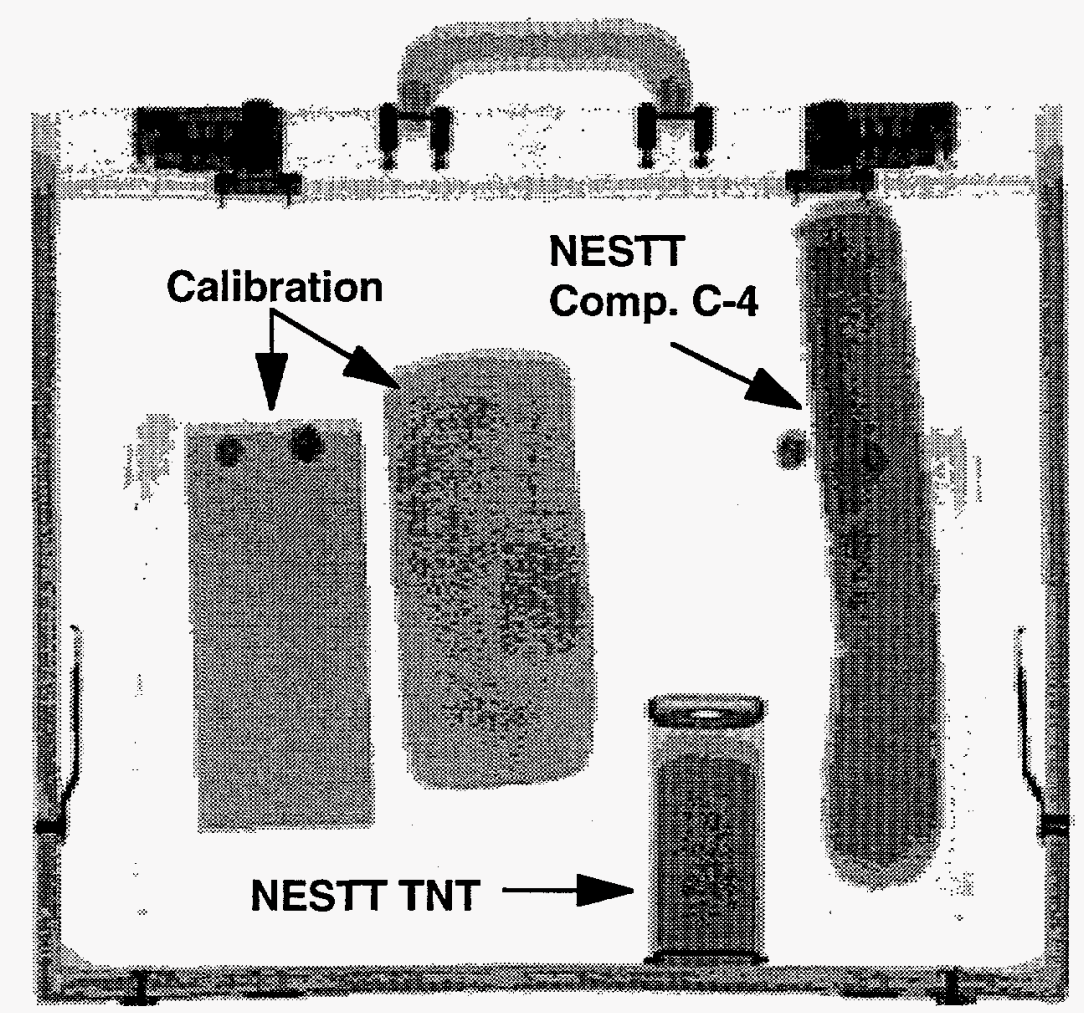

Figure 3. NESTT Comp. C-4 as viewed by VIVID's x-ray detection equipment.

\section{NESTT K-9 Results}

In contrast to instruments, the method by which canines detect explosives is not well understood. There are a variety of training procedures with strong proponents for each method. The NESTT canine testing provided a unique opportunity to gain some insight into the various programs since materials from one batch were provided to all the participants.

Test samples were carefully prepared to insure that their "odor signatures" were the same as for the parent explosives. Silica fused at high temperature was used as the diluent and as packing material for shipping the samples. This minimized the possibility of odor contamination by other organic compounds. As a check mass spectrometer analyses were done. Figure 4 shows that the vapor collected from TNT was identical to that from the NESTT TNT. 

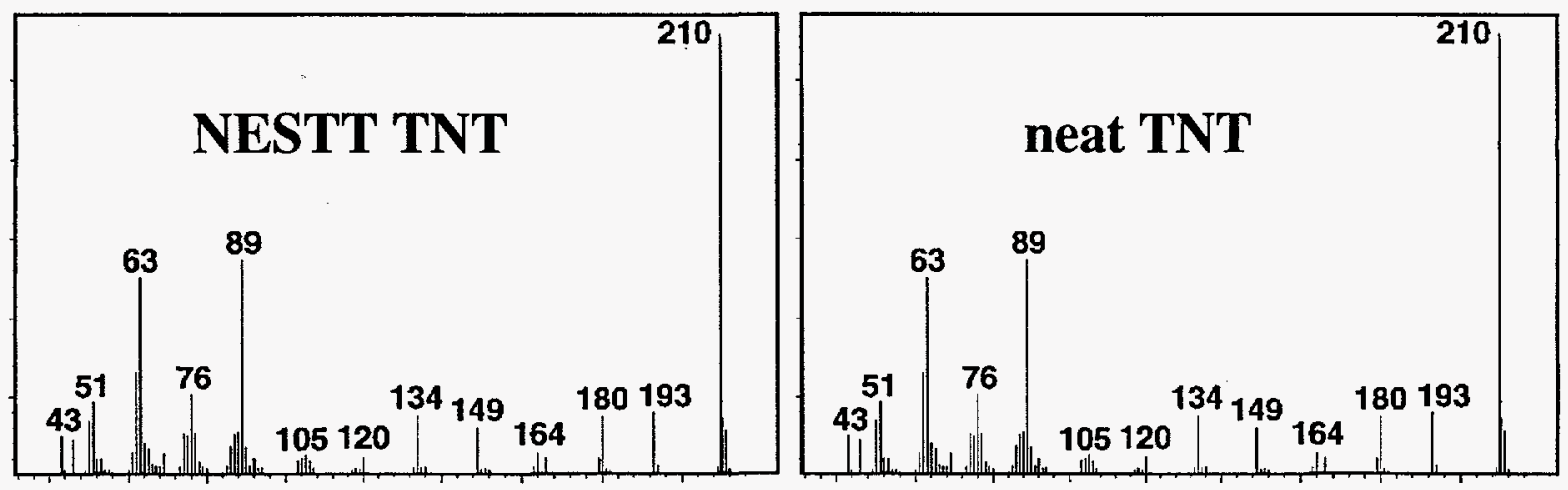

Figure 4. Mass spectral analyses of NESTT TNT vapor and neat TNT vapor.

The test program involved over 50 handler/K-9 teams from 15 US and foreign agencies. The results were varied. Some agency's dogs gave strong positive reactions to both NESTT TNT and NESTT Comp. C-4. Comments were:

"All 19 dogs gave strong and immediate positive alerts to the NESTT explosives."

"All (4) dogs .... responded to NESTT ... just as to real explosives."

".... trained .... dogs (2) and 2 dogs in 5 th week of training detected the .... materials ...."

"Dogs (6) had no problems with NESTT .... Identical response as with real explosives."

"All dogs (3) detected both NESTT materials"

Some agency's dogs had mixed or almost no reaction to the NESTT formulations. Comments were:

".... no problems with the NESTT TNT .... only 1 of 9 indicated on the NESTT Comp. C-4"

"... 4 dogs .... all NESTT samples ... detected .... but not as spontaneous or as sure"

".... NESTT TNT: .... 5 positive, 3 unsure $\& 3$ no interest ....

NESTT Comp. C-4: .... 4 positive, 6 unsure $\mathcal{E} 1$ no interest"

Four agencies dogs did not detect the NESTT materials - (some interest shown by a few dogs)

One agency trained 3 new dogs on both the NESTT TNT and NESTT Comp. C-4. These untrained dogs were taken from the explosive dog training pool. They were trained with the four-hole variable method followed by training in a barracks type environment. After this training the dogs were able to detect actual TNT and Comp. C-4 with $100 \%$ accuracy. 
The results, in general, coupled with vapor analysis verify that the NESTT materials have authentic "odor signatures". An attempt is now under way to see if the negative results could be due to contamination of the training samples over a period of time. A material with a changing "odor signature" that is used to reinforce performance with a reward could be the problem.

\section{NESTT Role in Counter-Terrorism Program}

The beta test program results show that NESTT materials can benefit explosive detection programs. For canine training they would minimize the possibility of contamination. There would be one production source with careful quality control and individual sealed samples. Because of their non-hazardous nature they can be easily stored separately and, hence, cross contamination of samples is avoided since the materials do not require centralized storage in an explosives magazine.

More cost effective training is possible. Realistic training sites and scenarios could be used. The training materials can be stored nearby and not in remote explosive magazines. Large quantities can be used safely in training for the detection of car or truck size bombs. Perhaps the most important aspect of the NESTT materials is that they eliminate the costs associated with training explosives handlers and explosives shipping and storage. In addition, these materials can be disposed of as non-explosive waste.

\section{References}

1. GenCorp Aerojet. 1940 Alabama Ave, P.O. Box 1322, Sacramento, CA 95813-6000, tel: 916-351-8554

2. Quantum Magnetics, 11578 Sorrento Valley Rd., San Diego, CA 92121.

3. Thermedics Detection Inc., 220 Mill Rd., Chelmsford, MA 01824.

4. Invision Technologies, Inc., 3420 E. Third Ave., Foster City, CA 94404.

5. VIVID Technologies Inc., 590 Lincoln St., Waltham, MA 02154.

\section{Acknowledgements}

The authors would like to acknowledge the assistance of Dr. B. Andresen and Mr. R. Whipple for making mass spectrometry measurements on NESTT samples. The help given by Dr. R. Atkins, Ms. J. H. de Pruneda, and Dr. M. Anastasio in developing this project has been invaluable. 